Bulletin of Pharmaceutical Sciences
Assiut University
Website: http://bpsa.journals.ekb.eg/
e-mail: bullpharm@aun.edu.eg

\title{
COMPARISON OF THE EFFECT OF VITEX AGNUS AND SALVIA OFFICINALIS EXTRACT AT CALCIUM, PHOSPHORUS AND VITAMIN D LEVELS IN POSTMENOPAUSAL WOMEN REFERRING TO BONE MINERAL DENSITOMETRY CENTER: A RANDOMIZED, DOUBLE-BLIND, PLACEBO-CONTROLLED TRIAL
}

Afsaneh Zeidabadi ${ }^{1}$, Masoumeh Emamghoreishi ${ }^{2}$, Mohammad Hosein Dabbaghmanesh ${ }^{3}$, Majid Dejbakhat ${ }^{4}$, Mohammad Reza Sasani ${ }^{5}$ and Marzieh Akbarzadeh ${ }^{6 *}$

${ }^{1}$ M.Sc. of Midwifery, School of Nursing and Midwifery, Shiraz University of Medical Sciences, Shiraz, Iran

${ }^{2}$ Department of Pharmacology, School of Medicine, Shiraz University of Medical Sciences, Shiraz, Iran

${ }^{3}$ Professor of Endocrinology, Department of Internal Medicine, Endocrine and Metabolism Research Center, Shiraz University of Medical Sciences, Shiraz, Iran

${ }^{4}$ Department of Radiology, Medical Imaging Research Center, School of Medicine, Shiraz University of Medical Sciences, Shiraz, Iran

${ }^{5}$ Department of Nursing, School of Nursing and Midwifery, Shiraz University of Medical Sciences, Shiraz, Iran

${ }^{6}$ Maternal-fetal Medicine Research Center, Department of Midwifery, School of Nursing and Midwifery, Shiraz University of Medical Sciences, Shiraz, Iran

\begin{abstract}
Osteoporosis is an important problem in women's health, one of the consequences of which is bone fracture. This clinical trial was performed in 2015 on 99 (33 patients per group) postmenopausal women referred to the bone mineral densitometry center. The first group received one Agnugol tablet (contains 3.2-4.8 mg dry extract of Vitex agnus castus, the second group received three Salvigol tablets (each contains $100 \mathrm{mg}$ Salvia officinal is dry extract daily and the third group three placebo tablets per day for 3 months. Calcium, phosphorus and vitamin D levels were compared before and after the intervention. Results of paired t-test showed that the mean of calcium and phosphorus level increased after intervention in the Vitex agnus and salvia officinalis extract groups, but there was no significant difference in the control group. LSD follow-up test was used, showing that the mean difference of calcium and phosphorus score between the Vitex agnus, S. officinalis extract and control groups was significant in pairwise comparisons. However, the difference between the score of phosphorus level in Vitex agnus and S. officinalis extract groups was not significant after the intervention. After intervention, the mean of vitamin D increased by 2.4 units in the Vitex agnus group compared to before the intervention. However, there was no statistically significant difference between the Vitex agnus and control groups after the intervention compared to before it. The Vitex agnus was effective in increasing calcium, phosphorus and vitamin D level, while $S$. officinalis extract was effective in increasing the level of calcium and phosphorus.
\end{abstract}

\section{INTRODUCTION}

Osteoporosis is a systemic skeletal disorder associated with bone loss at bone volume and loss of the microstructure of the bone tissue ${ }^{1}$. The changes of Osteoporosis increase the fragility of the bone and lead to an increased risk of bone fracture that is the

Received in 5/6/2021 \& Accepted in 17/7/2021

*Corresponding author: Marzieh Akbarzadeh, E-mail: marzieh.akhbar@gmail.com 
clinical outcome of osteoporosis ${ }^{2}$. Causes of this disorder include a reduction in sex hormones after menopause, insulin-like growth factor deficiency, vitamin D deficiency, a decrease in calcitriol in the kidney and bone, lack of cytokines, increased activity of osteoclasts caused by decreased estrogen levels, disruption in vitamin $\mathrm{D}$ activity and disruption in calcium absorption ${ }^{3}$.

The role of vitamin $\mathrm{D}$ in the bone metabolism, calcium and phosphorus, osteoporosis onset and decreased muscle strength, on the one hand, and the increased risk of falls and fractures, on the other hand, are still the most important issues for specialists in this field ${ }^{4}$. In addition, various studies indicate that about one billion people worldwide suffer from deficient levels of vitamin $\mathrm{D}^{5}$. This issue is not only related to developing countries, and it has been estimated that more than $50 \%$ of the world's population has a shortage of vitamin $\mathrm{D}$ in a serum level below $30 \mathrm{ng} / \mathrm{mL}^{6 \& 7}$.

Increase of the efficiency of calcium absorption (possibly due to increased exposure to vitamin D under the influence of estrogen induction) and the direct role of estrogen receptors in osteoblasts are important potential factors in this regard ${ }^{8}$. Estrogen is a golden standard treatment for osteoporosis prevention. On the one hand, study findings suggest that hormone therapy is associated with complications such as cardiovascular disease, stroke, pulmonary embolism, breast cancer, vaginal bleeding, and some serious dangers ${ }^{9 \& 10}$. On the other hand, some researchers have argued that although the use of menopausal hormone therapy has been questioned over recent years in prevention of osteoporosis due to security concerns, this issue needs to be reconsidered according to the latest reports of more agreement on the greater benefits/risks originally expressed in postmenopausal women. This is because the osteoporosisrelated fractures can significantly increase the mortality and morbidity of women ${ }^{11}$. Different therapies for osteoporosis are available. Most of these drugs are anti-refractory agents that nutritional sources of calcium and vitamin D are ideal ${ }^{12}$.

During the past 25 years, aminobisphosphonates, either orally or intravenously, have remained the dominant and first-line treatment for osteoporosis. These risk factors reduce the risk of spinal fractures by $70 \%$, hip fractures by $40-50 \%$, and non-vertebral fractures by $50-80 \%{ }^{13}$.

Complementary and Alternative Medicine (CAM) is also one of the treatments that is today popular among menopausal women, particularly in postmenopausal women ${ }^{14}$. Among complementary therapies, the change in lifestyle, nutrition, regular exercise, treatment by vitamin $\mathrm{E}$ regimen, homeopathy, relaxation techniques, reflexology, yoga, aromatherapy, acupuncture, massage therapy and herbal medicine can be mentioned ${ }^{15 \& 16}$.

Conducted studies showed that phytoestrogens played a role in the bone health ${ }^{16}$ and contributed to strengthened bone density by preventing bone loss. Phytoestrogens, due to the vasodilator effect, play a role in the bone health by increasing nitric oxide, in addition to vascular expansion, and by inhibiting the activity of osteoclasts and macrophages ${ }^{17}$.

On the other hand, some studies on the effects of phytoestrogens on the bone mass density (BMD) or bone turnover are largely contradictory. Currently, in some studies, the use of phytoestrogens is not recommended for menopausal osteoporosis. Therefore, hormone replacement therapy (HRT) is recommended to be considered for the prevention of osteoporosis $^{12}$.

There is no study on the effect of Vitex agnus and $S$. officinalis extract on the prevention of osteoporosis in postmenopausal women in Iran and there few studies conducted on the effect of these two plants on physical and psychological symptoms. The present study was carried out to evaluate the effect of Vitex agnus and S. officinalis extract on some osteogenic factors (calcium, phosphorus, vitamin D serum) in postmenopausal women referred to bone mineral densitometry center of Nemazee Hospital in Shiraz.

\section{MATERIAL AND METHODS}

This A randomized, double-blind, placebo-controlled trial was conducted in 2015 in Shiraz. The study population consisted of postmenopausal women referred to bone mineral densitometry center of Namazi Hospital. 
The sample size for each group was estimated to be 31 individuals by using Philip et al.'s $(2015)^{18}$ study and its generalization into three groups with confidence level of $95 \%$ and the powering test of 0.8 . Finally, with a 5\% probability of drop-out, 99 people were enrolled in this study and with Lost of 10 people in follow in three groups during the study, 89 of them completed the study (Figure 1)..A simple purposive sampling method was used in this study. Samples were randomly assigned to three groups of $\mathrm{A}, \mathrm{B}$ and $\mathrm{C}$, using random permuted blocks. The groups were included in the study after obtaining the written consent.

The inclusion criteria in this study were as follows: postmenopausal women who gave their written consent, no use of certain drugs that affect bone density and any hormonal medication, postmenopausal women who had received supplements of calcium and vitamin D., women who were osteopenic but were not treated with osteogenic drugs, and no sign of sensitivity to herbal medicine. Exclusion criteria in this study included allergic reaction to a drug and diagnosis of a disease during the study that required the use of drugs that affect bone density.

\section{Intervention methods}

We selected the study samples from patients who referred to bone mineral densitometry center. Then, the eligible women were randomly divided into three groups of Agnugol tablets-, Salvigol tablets-, and placebo-taking groups.. Tablets used for the intervention group were made by the Goldaru Pharmaceutical Company in Iran and the placebo tablets were made at Shiraz Faculty of Pharmacy. Then, they completed the written consent form and personal information form for the intervention. Then, they were introduced to the laboratory for calcium, phosphorus and vitamin $\mathrm{D}$ level tests. In the next step, the first intervention group received one 3.2-4.8 mg Agnugol tablet as a daily dose, the second intervention group received three $100 \mathrm{mg}$ Salvigol tablets and the third group received three placebo tablets per day for three months.

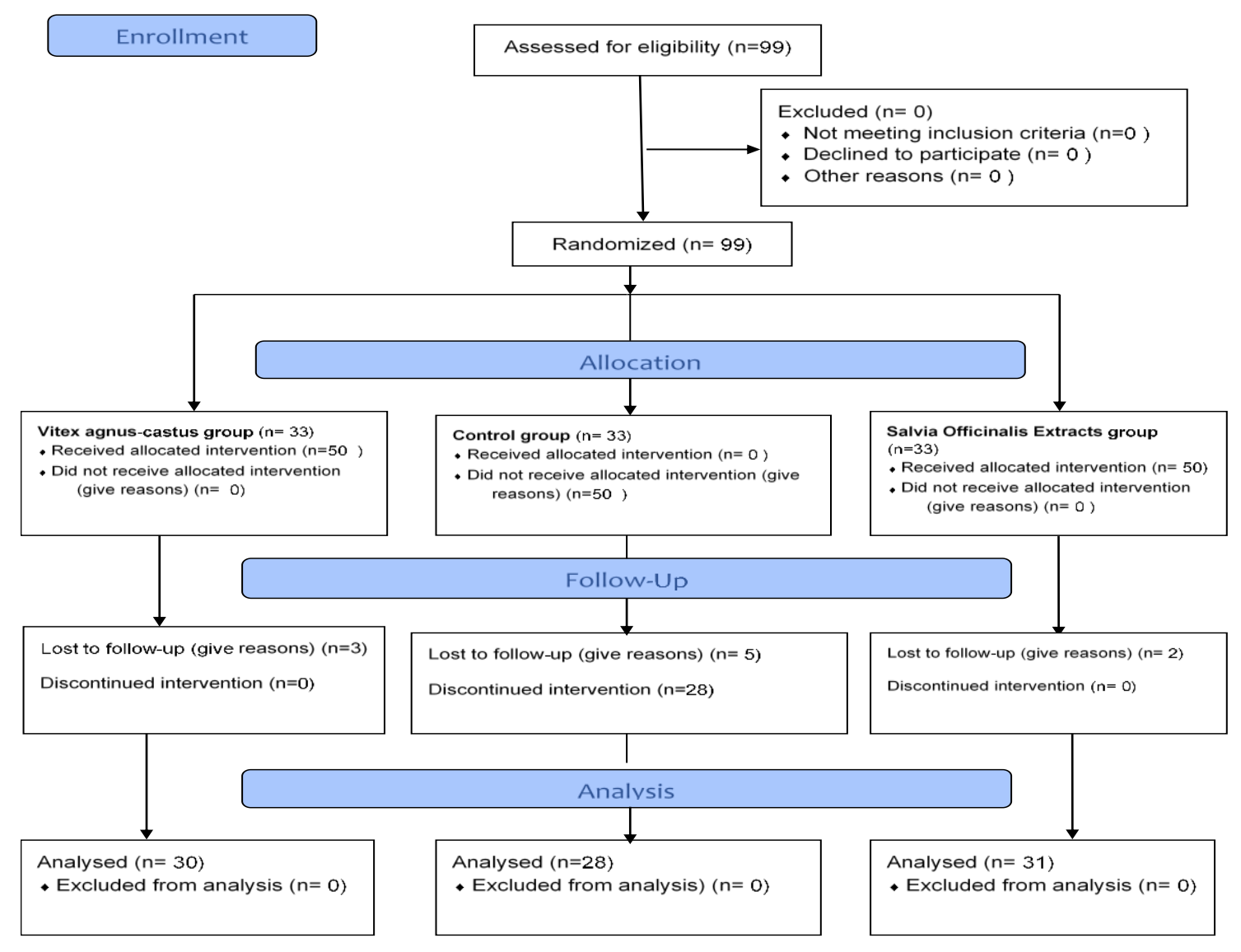

Fig1: CONSORT Diagram 
After three months, the tests were repeated and the results were analyzed by a statistician. Double-blindness in this study was in the pharmaceutical form of the tablets in three groups and their size was slightly different, but the subjects could not see each other. Moreover, the researcher put the tablets in black packs so that the contents of the tablets in each pack was not clear.

\section{Statistical analysis}

Data analysis was performed using SPSS16 software. For data analysis, Chi-square test, analysis of variance (ANOVA) and paired t-test were used. Least Significant Difference (LSD) follow-up test was used if there was a significant analysis of variance.

\section{RESULTS AND DISCUSSION}

\section{Results}

According to the paired t-test, there was an increase in the mean calcium $(0.5$ and 0.6 units) in the Vitex agnus and S. officinalis extract groups, respectively, after the intervention compared to before it, which showed a significant increase in calcium $(\mathrm{p}<$ 0.001 ). However, there was no significant difference in the control group $(\mathrm{p}=0.5)$.

Also, the mean of calcium analysis before and after the intervention was the same in the three groups, using ANOVA. The three groups had the same level of mean calcium before and after the intervention $(\mathrm{p}=0.259)$ (Table 1$)$.
According to the paired t-test results, there were significant phosphorus level increases of 0.6 and 0.5 units $(\mathrm{p}<0.001)$ in the Vitex agnus and $\mathrm{S}$. of ficinalis recipients, respectively, after the intervention compared to before it. While, there was no such significant difference in the control group $(\mathrm{p}=0.083)$.

Also, the results of ANOVA test showed that the mean phosphorus level was the same in the three groups before the intervention $(\mathrm{p}=$ 0.221 ), while after the intervention, there was a significant difference $(p<0.001)$. Using the test, we found that the difference between the mean score of phosphorus in the S. officinalis group and control group after the intervention was 0.55 while it was 0.78 in Vitex agnus group and control group after intervention, which was statistically significant in both plants $(\mathrm{p}<0.001)$. However, this difference between the Vitex agnus and S. officinalis group after the intervention was 0.23 , which was not statistically significant $(\mathrm{p}=0.068)$ (Table 2).

According to paired t-test results, there was an increase in the mean of vitamin D (4.2 units) in the Vitex agnus groups after the intervention compared to before it $(\mathrm{p}<0.001)$. However, there was no significant difference in the control group $(p=0.377)$. Also, the result of the ANOVA test showed that the mean of vitamin $\mathrm{D}$ was the same in the three groups before and after the intervention $(\mathrm{p}=0.476)$ (Table 3).

Table 1: The comparison of serum calcium levels before and after in the two intervention groups and control group

\begin{tabular}{|c|c|c|c|c|c|c|c|}
\hline \multirow{2}{*}{$\underset{(\mathbf{m g} / \mathbf{d l})}{\mathrm{Ca}}$} & Salvia Group & $\begin{array}{l}\text { Vitex } \\
\text { Group }\end{array}$ & $\begin{array}{l}\text { Control } \\
\text { Group }\end{array}$ & \multirow[t]{2}{*}{ p-value ${ }^{b}$} & \multirow[t]{2}{*}{ f } & \multirow{2}{*}{$\begin{array}{c}\text { Df } \\
\text { (between) }\end{array}$} & \multirow{2}{*}{$\begin{array}{c}\text { Df } \\
\text { (within) }\end{array}$} \\
\hline & $\mathrm{M} \pm \mathrm{SD}$ & $\mathrm{M} \pm \mathrm{SD}$ & $\mathrm{M} \pm \mathrm{SD}$ & & & & \\
\hline Before & $9.5 \pm 0.6$ & $9.5 \pm 0.5$ & $9.8 \pm 0.5$ & 0.061 & 2.897 & 2 & 86 \\
\hline After & $10.1 \pm 0.5$ & $10 \pm 0.5$ & $9.9 \pm 0.5$ & 0.259 & 1.372 & 2 & 86 \\
\hline CV & 0.6 & 0.5 & 0.1 & $<0.001$ & & & \\
\hline p-value ${ }^{a}$ & $<0.001$ & $<0.001$ & 0.50 & & & & \\
\hline
\end{tabular}

a. paired sample t-test

b. One-way ANOVA 
Table 2: The comparison of serum Phosphorus levels before and after the two intervention groups and control group

\begin{tabular}{|c|c|c|c|c|c|c|c|}
\hline \multirow{2}{*}{ P (mg/dl) } & $\begin{array}{c}\text { Salvia } \\
\text { Group }\end{array}$ & $\begin{array}{c}\text { Vitex } \\
\text { Group }\end{array}$ & $\begin{array}{c}\text { Control } \\
\text { Group }\end{array}$ & \multirow{2}{*}{ p-value $^{\mathbf{b}}$} & f & Df (between) & $\begin{array}{c}\text { Df } \\
\text { (within) }\end{array}$ \\
\cline { 2 - 5 } M \pm SD & M \pm SD & M \pm SD & & & & 86 \\
\hline Before & $3.8 \pm 0.5$ & $3.9 \pm 0.4$ & $3.8 \pm 0.5$ & 0.221 & 1.53 & 2 & 86 \\
\hline After & $4.3 \pm 0.5$ & $4.5 \pm 0.5$ & $3.7 \pm 0.5$ & $<0.001$ & 19.18 & 2 & \\
\hline CV & 0.5 & 0.6 & 0.1 & $<0.001$ & & & \\
\hline p-value $^{\mathbf{a}}$ & $<0.001$ & $<0.001$ & 0.083 & & & & \\
\hline
\end{tabular}

a. Paired sample t-test

b. One-way ANOVA

Table 3: The comparison of serum Vitamin D levels before and after the two intervention groups and control group

\begin{tabular}{|c|c|c|c|c|c|c|c|}
\hline \multirow{2}{*}{$\begin{array}{c}\text { Vit- } \\
\text { D(mg/dl) }\end{array}$} & $\begin{array}{l}\text { Salvia } \\
\text { Group }\end{array}$ & $\begin{array}{c}\text { Vitex } \\
\text { Group }\end{array}$ & $\begin{array}{l}\text { Control } \\
\text { Group }\end{array}$ & \multirow[t]{2}{*}{$\begin{array}{c}\text { p- } \\
\text { value }^{b}\end{array}$} & \multirow[t]{2}{*}{$\mathbf{f}$} & \multirow[t]{2}{*}{$\begin{array}{c}\text { Df } \\
\text { (between) }\end{array}$} & \multirow[t]{2}{*}{$\begin{array}{c}\text { Df } \\
\text { (within) }\end{array}$} \\
\hline & $\mathrm{M} \pm \mathrm{SD}$ & $\mathrm{M} \pm \mathrm{SD}$ & $\mathrm{M} \pm \mathrm{SD}$ & & & & \\
\hline Before & $33.3 \pm 20.1$ & $26.9 \pm 14.4$ & $27.9 \pm 16.5$ & 0.303 & 1.212 & 2 & 86 \\
\hline After & $35.4 \pm 19.4$ & $31.1 \pm 16.9$ & $29.7 \pm 19.8$ & 0.476 & 0.749 & 2 & 86 \\
\hline $\mathrm{CV}$ & 2.1 & 4.2 & 1.8 & 0.484 & & & \\
\hline p-value ${ }^{a}$ & 0.078 & $<0.001$ & 0.377 & & & & \\
\hline
\end{tabular}

a. Paired sample t-test

b. One-way ANOVA

\section{Discussion}

In this study, although the mean of calcium increased significantly after the intervention compared with before it, this increase was not significant in comparison to the control group $(\mathrm{P}=0.259)$. This insignificant effect of the Vitex agnus and S. officinalis extract on the control group in our study may be due to the use of calcium supplementation by all postmenopausal women who were included in the study.

In a study carried out by Hoylian et al. (2014), the effect of olive on mice was investigated. In this study, 120 mice were divided into 4 groups (30 mice in each group). The first group was the control group, the second one was ovarian removed group, the third group was ovarian removed + olive group, and the fourth one was ovarian removed + estradiol group. The amount of calcium in the olive treatment group did not change significantly compared to the control group, which is consistent with our study. The reason for this inconsistency in terms of significance may be the oscillations of calcium in the blood during osteoporosis ${ }^{19}$. In another study conducted by Noorafshan et al. (2015), the effect of black and white olive extract (containing phytoestrogen flavonoids) on 90 mice was studied ${ }^{20}$. The obtained result of no change in the calcium level in this study was consistent with the finding of our study. However, in a study by Qiong et al. (2012), the effect of $S$. officinalis extract (Danshen) on osteoporosis was studied. In this study, 4.5 $\mathrm{mg} / \mathrm{kg}$ prednisone was given to 4-month-old mice every day to cause osteoporosis in them. In these mice, calcium, phosphorus, magnesium and hydroxyproline levels decreased. Next, the blue extract of the root of S. officinalis was applied for 12 weeks. Finally, calcium and BMD levels increased in mice, but the level of phosphorus, magnesium and $\mathrm{PH}$ did not change $^{21}$. Their results, have not been consistent with those of our study on calcium.

Although the two intervention groups are very similar in the effectiveness of serum calcium score, Salvia Officinalis Extract has performed better than vitex in improving serum calcium score because the changes after the intervention are more than vitex compared to before the intervention in the $S$. officinalis group. Although this amount is not significant.

In our study, the amount of phosphorus in the two intervention groups was significantly different from that of the control group $(\mathrm{p}=$ 
0.083). In this regard, a study by Hasan et al. (2013) examined the effects of soy and sesame on 36 mice: First, the control group; second, soybeans group; third, sesame group; fourth, ovarian removal group; fifth, ovarian removed+ soybeans group; and sixth, ovarian removed+ sesame group. Six mice were placed in each group. Calcium and phosphorus level of the blood increased in groups 5 and 6 , which were menopausal and had received phytoestrogens ${ }^{22}$.

In the study of Alkami et al. (2015), the phosphorus level increased after the herb extracts and the use of phytoestrogens, which is consistent with the present study findings ${ }^{23}$.

But Zhang et al. (2014) studied the effect of isoflavones derived from the hypericum on osteogenic factors in Wistar rats. Calcium and phosphorus levels in the group treated with isoflavone increased with a higher dose ${ }^{24}$. This decrease in phosphorus level is contrary to our study results, which may be due to the dose of isoflavone, which has been associated with a higher reduction in these factors.

In fact, calcium and phosphorus are important components of the body's skeletal system and their adequate level can prevent osteoporosis and the risk of subsequent fracture $^{19}$. Loss of calcium and phosphorus level makes problems in bone deposition. Basically, the reasons for calcium loss after menopause or ovarian removal are as follows:1) Calcium and phosphorus intake from the intestines is reduced due to the decrease in vitamin $D$; 2) Resistance of intestinal tract to vitamin D increases; 3) Renal excretion of calcium increases; and 4. Estrogen reduction causes a change in the expression of many distal kidney tubule proteins that reduce calcium reuptake. Phytoestrogens compensate this estrogen deficiency to some extent and increase the calcium and phosphorus level in the blood; his result is consistent with those of our study ${ }^{25}$.

In animals that are estrogen deficient due to ovarian resection, high levels of parathyroid hormone cause them to lose bone density. In other words, a decrease in estrogen levels in women increases bone sensitivity to the function of parathyroid hormone, resulting in bone destruction and decreased bone density. However, removal of the ovary causes hyperparathyroidism, which may cause calcium changes and the release of calcium from the bone and its loss ${ }^{26}$

The mean of vitamin $\mathrm{D}$, before and after the intervention, was significant different in the Vitex agnus group, but the mean of vitamin $\mathrm{D}$ in the $S$. officinalis group $(\mathrm{p}=0.078)$ and control group was not significantly different $(p=0.377)$. In this regard, Marini et al. (2007) investigated the effect of genistein (phytoestrogens) in postmenopausal women. They divided 389 postmenopausal women for 24 months into two groups of treatment with genistein (54 mg per day) and treatment with placebo, while both groups received calcium and vitamin D supplements. Finally, it was found that calcium and vitamin D levels in both groups increased significantly, but no significant difference was observed in the treatment group compared to the placebo ${ }^{27}$. In a clinical trial carried out by Filip et al. (2015), the effect of polyphenolic compounds on olive extracts in postmenopausal women have been investigated.

The study of Filip et al. have shown that, alkaline phosphatase level decreased and calcium, phosphorus and vitamin D level increased in the olive treated group compared to the control group ${ }^{18}$. These results are not consistent with our study. The level of vitamin $\mathrm{D}$ in postmenopausal women with osteoporosis is $l^{28}{ }^{28}$. In other studies, vitamin D levels increased after estrogen therapy in postmenopausal women ${ }^{29 \& 30}$. The importance of this vitamin is very important and should be taken care of in order to balance it in the body. This vitamin increases the absorption of calcium and phosphorus from the lumen into the plasma by acting on the enterocytes of the small intestine, and also plays an essential role in the absorption of calcium from bone in the presence of parathyroid hormone. This vitamin, along with parathyroid hormone, improves the reabsorption of calcium from the distal tubules, which ultimately increases calcium and phosphorus levels and prevent muscle contractions following hypocalcemia. Calcium and phosphorus requirements are regulated by the production of vitamin $\mathrm{D}^{31}$.

Although the two intervention groups were very similar in their effects on calcium and phosphorus serum scores, S. officinalis group performance was better than the Vitex agnus group in terms of the improved scores of 
calcium and phosphorus serum. It was due to more changes in the $S$. officinalis group compared to the Vitex agnus group before and after the intervention.

\section{Conclusion}

After the intervention, calcium and phosphorus serum levels in the two Salvia officinalis and Vitex agnus groups were significantly higher than those before the intervention, but calcium and phosphorus levels increased significantly compared to the control group. The level of vitamin D serum in the Vitex agnus group after the intervention was significantly higher than before it, but it did not significantly increase compared to the control group. Moreover, there was no significant increase in the $S$. officinalis group after the intervention compared to the control group before the intervention.

\section{Ethics Approval and Consent to Participate}

This research was carried out in Nemazee Hospital after obtaining approval from the Ethics Committee of Shiraz University of Medical Sciences with the license number of IR.SUMS.REC.1394.185 dated in .2015 and also after registration on Iranian Clinical Trial website with the code number of 2015111713940N2 in Nemazee hospital. The postmenopausal women were enrolled in the study after signing an informed consent forms, if they wished to cooperate and if they observed the entry requirements. They were excluded from the study if they did not agree to continue the intervention

\section{Acknowledgement}

This article is a part of Afsaneh Zeidabadi's thesis, (thesis number: 94-10255, IRCT: 2015111713940N2). Researchers appreciate Research and Technology Department of Shiraz University of Medical Sciences. Research Improvement Center of Shiraz University of Medical Sciences and The authors would like to thank Center for Development of Clinical Research of Nemazee Hospital and Dr. Nasrin Shokrpour for editorial assistance.

\section{REFERENCES}

1. J. A. Kanis, E. V. McCloskey, H. Johansson, C. Cooper, R. Rizzoli, J. Y. Reginster, et al., "European guidance for the diagnosis and management of osteoporosis in postmenopausal women", Osteoporos Int, 24, 23-57 (2013).

2. J. Y. Reginster, "Antifracture efficacy of currently available therapies for postmenopausal osteoporosis", Drugs, 71, 65-78 (2011).

3. D. J. Hadjidakis," Androulakis, II, Bone remodeling", Ann N Y Acad Sci, 1092, 385-396 (2006).

4. M. T. Drake, B. L.Clarke and E. M. Lewiecki, "The pathophysiology and treatment of osteoporosis", Clin Ther, 37, 1837-1850 (2015).

5. M. F. Holick, "Vitamin D deficiency", $N$ Engl J Med, 357, 266-281 (2007).

6. Z. Xie, W. Xia, Z. Zhang, W. Wu, C.Lu, S. Tao, et al., "Prevalence of Vitamin D Inadequacy Among Chinese Postmenopausal Women: A Nationwide, Multicenter, Cross-Sectional Study", Front. Endocrinol (Lausanne), 9, 782 (2018).

7. S. J. Wimalawansa, M. S. Razzaque and N. M. Al-Daghri, Calcium and vitamin D in human health: Hype or real?, J Steroid Biochem Mol Biol, 180, 4-14 (2018).

8. L. Speroff, "Menopause and the perimenopausal transition", Clinical gynecologic endocrinology and infertility, 673-748 (2011).

9. T. Guttuso, Jr., R. Kurlan , M. P. McDermott and K. Kieburtz, "Gabapentin's effects on hot flashes in postmenopausal women: a randomized controlled trial", Obstet Gynecol, 101, 337-345 (2003).

10. K. M. Newton, S. D. Reed, A. Z. LaCroix, L. C. Grothaus, K. Ehrlich and J. Guiltinan, "Treatment of vasomotor symptoms of menopause with black cohosh, multibotanicals, soy, hormone therapy, or placebo: a randomized trial", Ann Intern Med, 145, 869-879 (2006).

11. F. Tremollieres, "Assessment and hormonal management of osteoporosis", Climacteric, 22, 122-126 (2019).

12. M. Gambacciani and M. Levancini, "Management of postmenopausal osteoporosis and the prevention of fractures", Panminerva Med, 56, 115-31 (2014).

13. New developments in osteoporosis treatment, Mayo Clin Health Lett, 18, 4 (2000). 
14. F. Borrelli and E. Ernst, "Alternative and complementary therapies for the menopause", Maturitas, 66, 333-343 (2010).

15. R. Pachman, J. M. Jones and C. L. Loprinzi "Management of menopauseassociated vasomotor symptoms: Current treatment options, challenges and future directions", Int J Womens Health, 2, 12335 (2010).

16. R. W. Wong and A. B. Rabie, "Effect of naringin collagen graft on bone formation", Biomaterials, 27, 1824-1831 (2006).

17. M. H. Eftekhari, Z. H. Rostami, M. J. Emami and H. R. Tabatabaee, "Effects of vitex agnus castus" extract and magnesium supplementation, alone and in combination, on osteogenic and angiogenic factors and fracture healing in women with long bone fracture", J Res Med Sci, 19, 1-7 (2014).

18. R. Filip, S. Possemiers, A. Heyerick, I. Pinheiro, G. Raszewski, M. J. Davicco, et al., Twelve-month consumption of a polyphenol extract from olive (Olea europaea) in a double blind, randomized trial increases serum total osteocalcin levels and improves serum lipid profiles in postmenopausal women with osteopenia", J Nutr Health Aging, 19, 77-86 (2015).

19. H. Liu, H. Huang, B. Li, D. Wu, F.Wang, $\mathrm{X}$. Zheng, et al., "Olive oil in the prevention and treatment of osteoporosis after artificial menopause", Clin Interv Aging, 9, 2087-2095 (2014).

20. A. Noorafshan, M. H. Dabbaghmanesh, N. Tanideh, F. Koohpeyma, R. Rasooli, M. Hajihoseini, et al., "Stereological study of the effect of black olive hydroalcoholic extract on osteoporosis in vertebra and tibia in ovariectomized rats", Osteoporos Int, 26, 2299-307 (2015).

21. Q. YU, L. CUI, T. WU, "The effect of three effective fractions of water extract of Danshen on glucocorticoidinducedosteoporosis in rats", Chinese Journal of Osteoporosis, 18, 695-699 (2012).

22. H. A. Hassan, A. M. El Wakf and N. E. El Gharib , "Role of phytoestrogenic oils in alleviating osteoporosis associated with ovariectomy in rats", Cytotechnology, 65, 609-619 (2013).
23. M. M. Elkomy and F. G. Elsaid F. G., "Anti-osteoporotic effect of medical herbs and calcium supplementation on ovariectomized rats", JOBAZ, 72, 81-8 (2015).

24. D. W. Zhang, Z. L. Wang, W. Qi and G. Y. Zhao, "The effects of Cordyceps sinensis phytoestrogen on estrogen deficiency-induced osteoporosis in ovariectomized rats", BMC Complement Altern Med, 14, 484 (2014).

25. N. K. Saleh and H. A. Saleh, "Olive oil effectively mitigates ovariectomy-induced osteoporosis in rats", BMC Complement Altern Med, 11, 10 (2011)

26. M. M. Elkomy and F. G. Elsaid. "Antiosteoporotic effect of medical herbs and calcium supplementation on ovariectomized rats". JOBAZ. 72, 81-88 (2015).

27. H. Marini, L. Minutoli, F. Polito, A. Bitto, D. Altavilla, M. Atteritano, et al.," Effects of the phytoestrogen genistein on bone metabolism in osteopenic postmenopausal women: a randomized trial", Ann Intern Med, 146, 839-847 (2007).

28. P. Lips, D. Hosking, K. Lippuner, J. MNorquist, L. Wehren, G. Maalouf, et al., "The prevalence of vitamin D inadequacy amongst women with osteoporosis: an international epidemiological investigation", J Intern Med, 260, 245-54 (2006).

29. L. Rejnmark, A. L. Lauridsen, C. Brot, P. Vestergaard, L. Heickendorff, E. Nexo, et $a l$. , "Vitamin D and its binding protein Gc: long-term variability in peri- and postmenopausal women with and without hormone replacement therapy", Scand J Clin Lab Invest, 66, 227-238 (2006).

30. S. Ziaei, M. Moghasemi and S. Faghihzadeh "Comparative effects of conventional hormone replacement therapy and tibolone on climacteric symptoms and sexual dysfunction in postmenopausal women", Climacteric, 13, 147-56 (2010).

31. A. Amiri, A. A. Karimi, H. Zakeri and L. Zamani, "Vitamin D deficiency and stroke", Journal of Fasa University of Medical Sciences, 2(3), 121-126 (2012). 


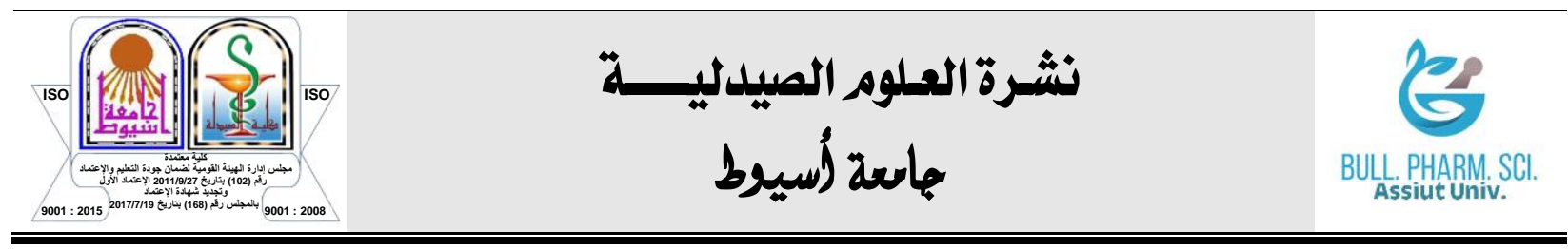

\section{مقارنة بين تأثير مستخلص كل من فيتكس أجنس و سالقيا أوفيشيناليس على التى}

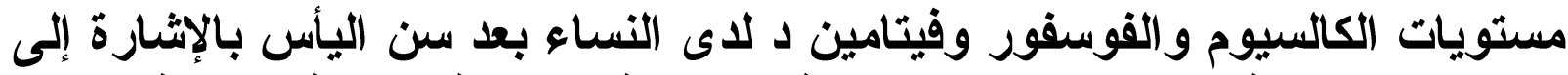
مركز قياس كثافة المعادن بالعظام: تجربة عشوائية مزدوجة التعمية خاضعة للتهية للتحم بالغفل

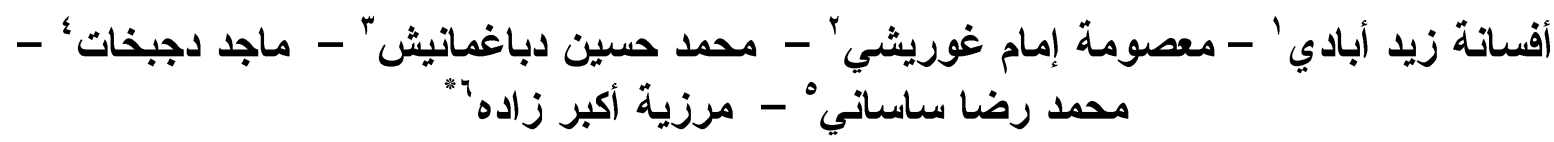

$$
\begin{aligned}
& \text { 'ماجستير القبالة ، كلية التمريض والقبالة ، جامعة شيراز للعلوم الطبية ، شيراز ، إيران }
\end{aligned}
$$

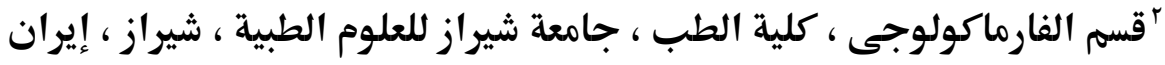

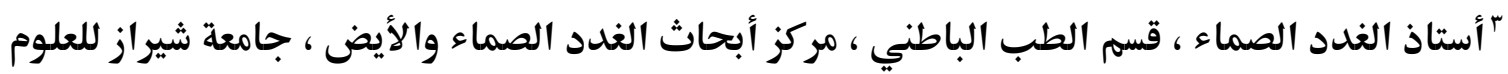

$$
\text { الطبية ، شيراز ، إيران }
$$

قُقم الأشعة ، مركز أبحاث التصوير الطبي ، كلية الطب ، جامعة شيراز للعلوم الطبية ، شيراز ، إيران

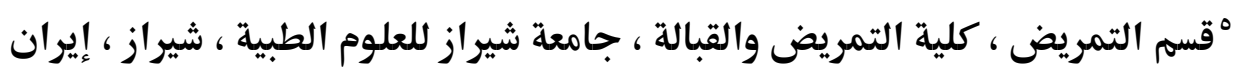

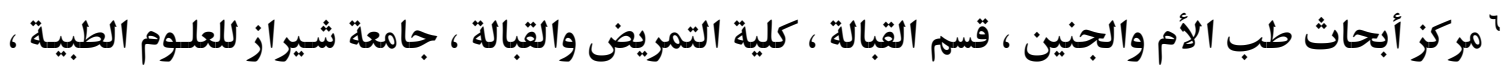

$$
\text { شيراز ، إيران }
$$

هشاشة العظام مشكلة مهمة في صحة المر أة ، ومن عو اقبها كسور العظام. أجريت هذه التجربة التباء

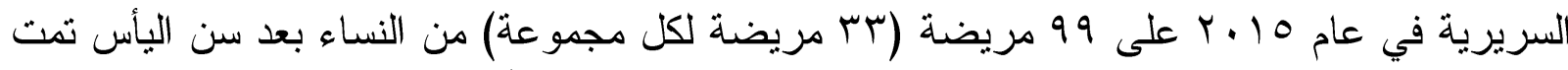

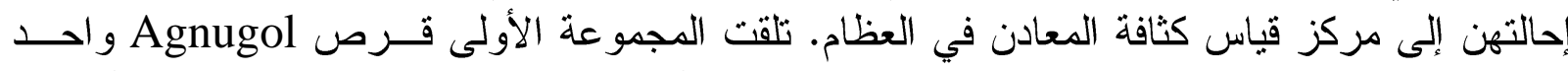

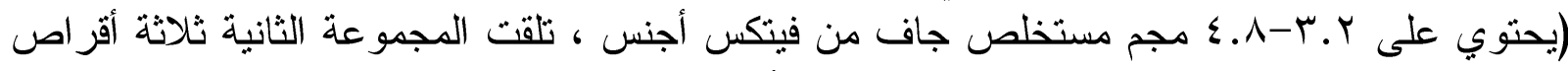
Salvigol

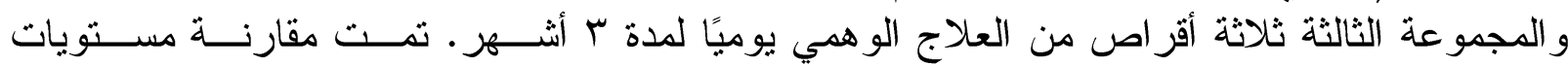

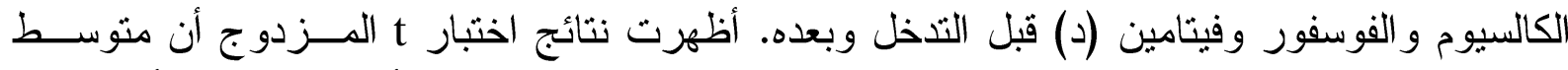

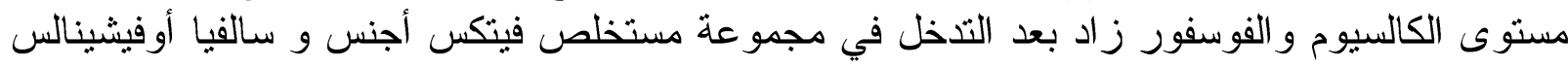

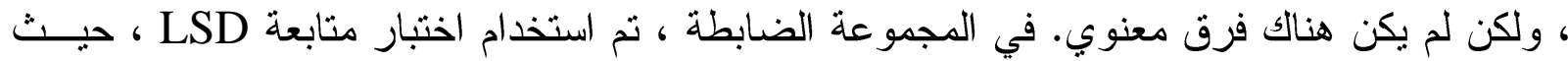

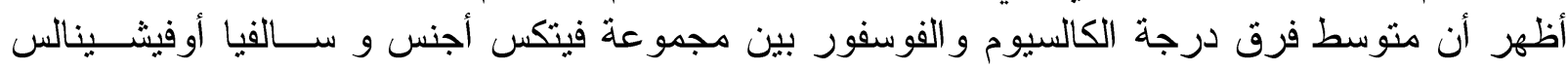

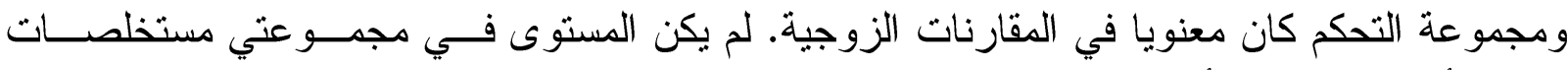

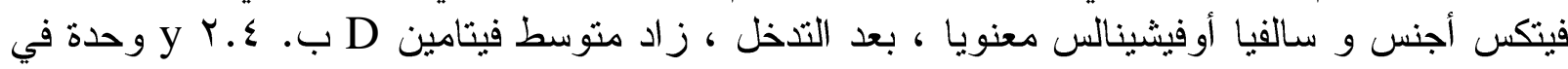

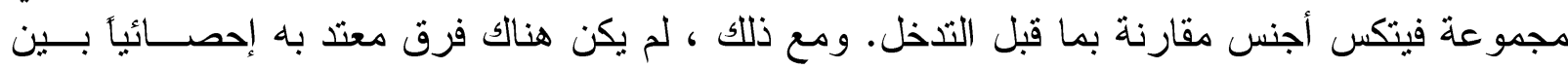




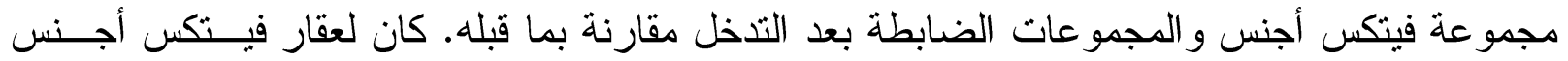

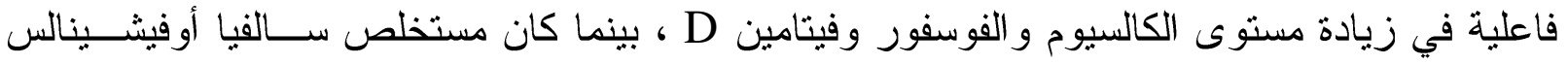
فعالاً في زيادة مستوى الكالسيوم و الفوسفور . 